\title{
Rocky Mountain Center for Conservation Genetics and Systematics
}

\section{Genetics in Conservation}

The use of molecular genetic tools has become increasingly important in addressing conservation issues pertaining to plants and animals. Genetic information can be used to augment studies of population dynamics and population viability, investigate systematics, refine taxonomic definitions, investigate population structure and gene flow, and document genetic diversity in a variety of plant and animal species. Further, genetic techniques are being used to investigate mating systems through paternity analysis, analyze ancient DNA samples from museum specimens, and estimate population size and survival rates using DNA as a unique marker. Such information is essential for the sound management of small, isolated populations or populations of concern and is currently being used by universities, zoos, the U.S. Fish and Wildlife Service, and numerous state fish and wildlife agencies.

\section{Pooling Expertise and Resources}

The Rocky Mountain Center for Conservation Genetics and Systematics (RMCCGS) was developed by the University of Denver (DU) and the U.S. Geological Survey, Fort Collins Science Center (USGS-FORT) to address the ever-growing need

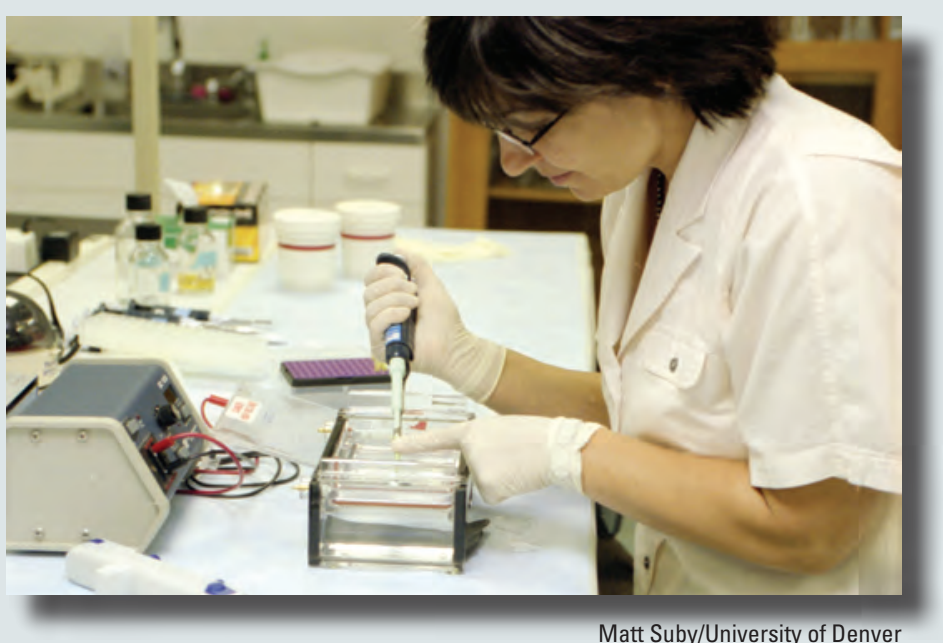

for research in these areas. The collaborative effort between DU and USGS combines different resources and philosophies, providing an academically rich and dynamic setting for conducting research. Further, the RMCCGS has additional partnerships with the Denver Museum of Nature and Science, the Denver Zoo, and the Denver Botanic Gardens. These institutions provide additional expertise, perspectives, and resources for the conservation of plants and animals. In addition, undergraduate and graduate students have the opportunity to interact with scientists of diverse academic backgrounds and to participate in scientific research with direct applications to conservation problems. The results are better interpretations and innovative, science-based solutions to ecological problems.

The RMCCGS is equipped for DNA sequencing and analysis of DNA fragments using state-of-the-art molecular laboratory equipment, including a capillary-based automated DNA sequencer and a variety of thermocyclers. The Center offers various types of genotyping methods. In addition, the RMCCGS contains a separate ultra-clean laboratory for ancient DNA work and a fully equipped computer lab for data analysis.

\section{Services}

At the RMCCGS, we routinely perform DNA extraction, sequencing, and fragment analysis and have used such techniques to generate information used by biologists to help manage species of concern. We welcome collaborators needing the aforementioned services. Using our newly developed rapid-capture technique, we have

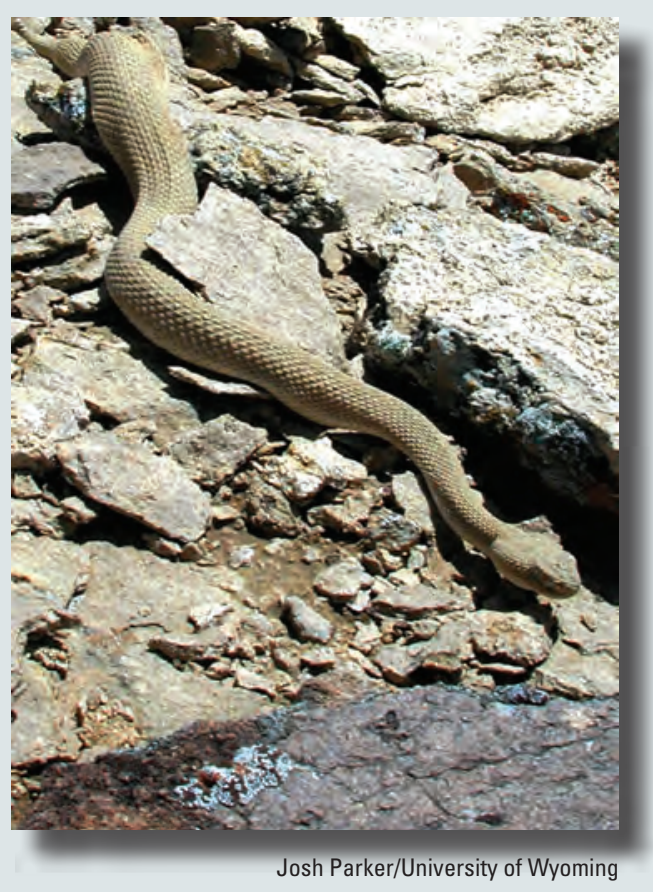
been successful in isolating microsatellites from numerous species (birds, mammals, reptiles, and invertebrates) that have effectively been used in population studies. We offer the service of microsatellite isolation for any interested parties. 


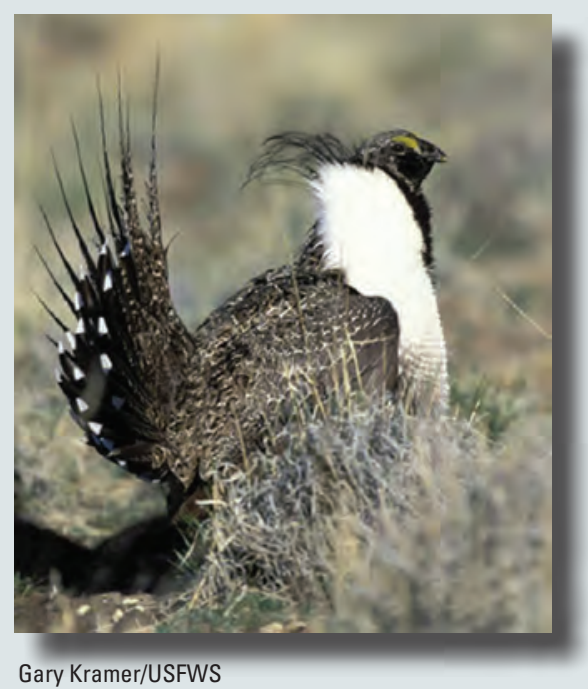

\section{Center Research}

We have used DNA sequence data (mitochondrial, chloroplast, and nuclear) along with DNA fragment data from nuclear microsatellites to document the population structure of many species, including Greater Sage-Grouse, Gunnison Sage-

Grouse, Mountain

Plover, Lesser Prairie-Chicken, Trumpeter Swan, Midget-Faded Rattlesnake, and Wood Frog. Information from these projects is being used to redefine taxonomic boundaries, investigate hybrid zones, and define distinct population segment and management units.

Our genetic techniques have allowed us to uniquely identify individuals for analysis of mating systems and mark-recapture

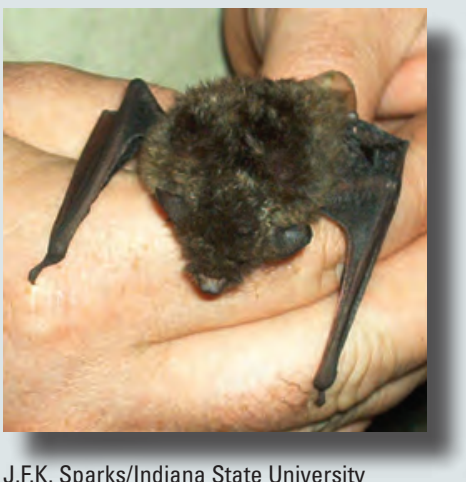
analysis to estimate population size. These techniques are currently being used on Gunnison Sage-Grouse, Greater Sage-Grouse, and the Indiana Bat. As a part of these projects, we are also perfecting the extraction of DNA from low-quantity, non-invasive samples such as feathers and excrement.

We are currently involved in a project on ancient tea trees in the Yunnan Province in China. Ancient tea gardens in the Province contain tea trees thousands of years old that have intrinsic value to minority cultures in China. Our project is an attempt to provide genetic verification of the origin of tea leaves from the ancient tea gardens. This confirmation allows them to be marketed so that the minority cultures maintaining those gardens are recognized and profit from sales, thereby helping to preserve their culture and improve socio-economic conditions.

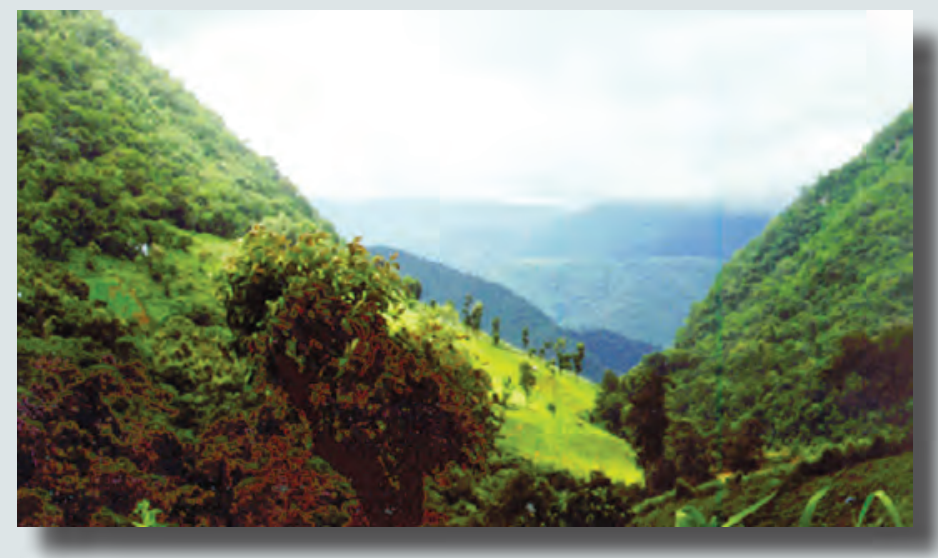

Richard Johnson/USGS

Our ancient DNA facility is being used to determine the sex of bones from the extinct Hawaiian Giant Goose. This information will help determine if abnormal bony outgrowths on wings and lamellar thickenings elsewhere on some skeletons allowed the wings to be used for aggressive male-male interactions.

Another project conducted in the ancient DNA facility is comparing the genetic make-up of modern populations of White-Tailed Kites in the western United States with ancient samples to determine the extent of a proposed genetic bottleneck in the 1930 s.

We have recently begun to use transposable ele-

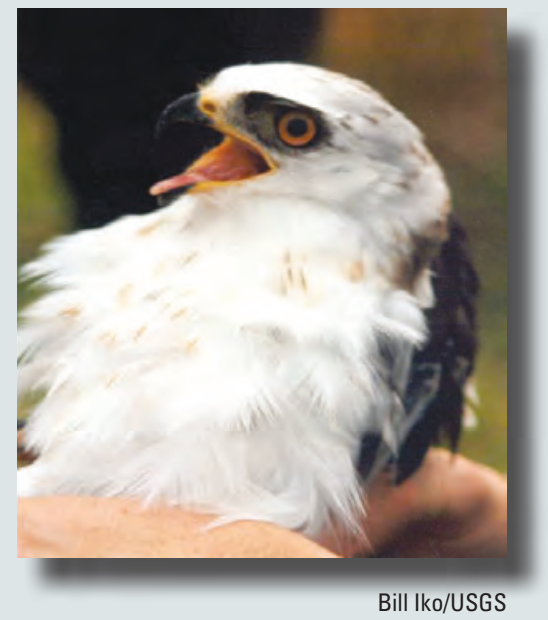
ments, specifically the chicken repeat 1 (CR1), for systematic studies of waterfowl. A rapid-capture technique developed at the RMCCGS allows for the efficient isolation of CR1 elements aiding in this study.

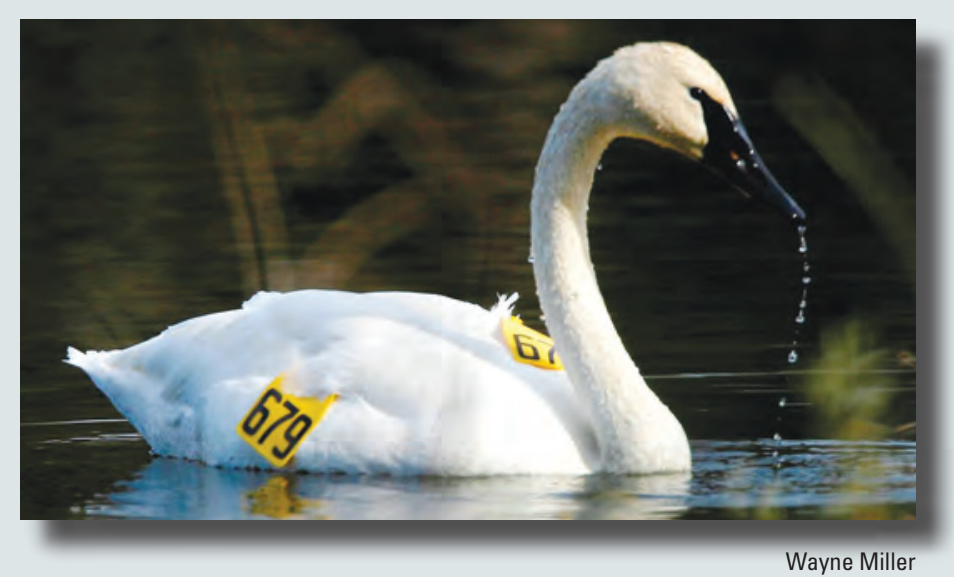

\section{Directors}

Drs. Tom Quinn (Department of Biological Sciences-DU) and Sara Oyler-McCance (USGS-FORT) serve as Center Co-Directors. Dr. Quinn was one of the first to apply molecular methods to the study of natural animal populations. Dr. OylerMcCance's molecular expertise is complemented by extensive previous field work with vertebrates.

For inquiries about science capabilities, research, services, or partnership opportunities, please visit our website at $<w w w . r m c c g s . u s g s . g o v>$.

Or, you may contact:

Thomas W. Quinn

Dept. of Biological

Sciences

University of Denver

Denver, CO 80208

Tel: 303.871 .3466

Fax: 303.871.3471

E-mail: tquinn@du.edu
Sara J. Oyler-McCance

U.S. Geological Survey

at: Dept. of Biological Sciences

University of Denver

Denver, CO 80208

Tel: 303.871 .7782

Fax: 303.871.3471

E-mail: sara_oyler-mccance@usgs.gov 